\title{
Consumer Skepticism (Does Consumer Believe on Advertisements?)
}

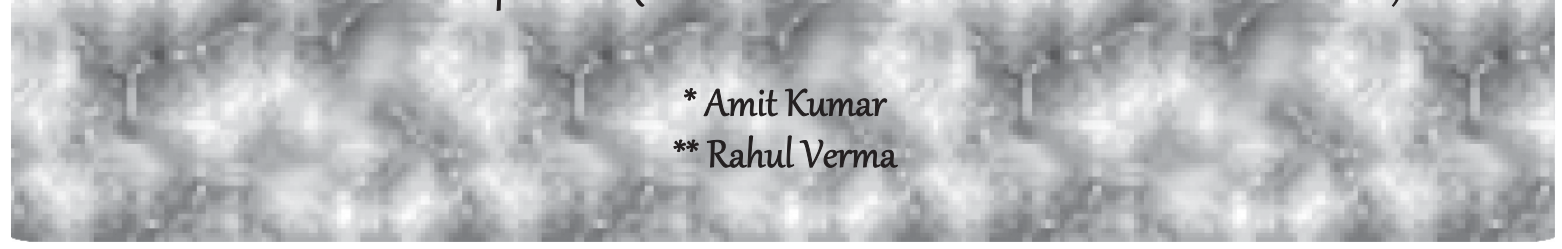

Effulgence

Vol. 12 No. 1

January - June, 2014

Rukmini Devi Institute of Advanced Studies

E-mail : effulgence@rdias.ac.in, Website : www.rdias.ac.in

http:/ / effulgence.rdias.ac.in/user/default.aspX

\begin{abstract}
The most important function of advertisements is to persuade the target group in the market to make it more known and increase the sales. Advertisement researchers examine the skepticism structure as a factor that can prevent the audience from persuasion. In advertisement field, skepticism is defined in two different ways; as an inclination or as an attitude. In this study, skepticism is accepted as an inclination and this inclination is argued within the frame of tactics from structural factors of advertisement. The factors used in advertisement are separated into two as informative and emotional tactics. At the same time, there are advertisements that consist of both the informative and emotional tactics. The main problem this research is to search the impact of the tactics used in the ads on skepticism.
\end{abstract} https://dx.doi.org/10.33601/effulgence.rdias/v12/i1/2014/88-96

Keywords: Skepticism, Advertisement, Informative \& emotional tactics.

\section{INTRODUCTION}

Cepticism toward advertising is defined as the general $\checkmark$ tendency toward disbelief of advertising claims. Skepticism is hypothesized as a general trait that varies across individuals and is related to general persuadability. The measure assesses a generalizable characteristics rather than response to specific ads or ad claims. Moreover, the construct is more limited than concept such as attitudes toward advertising in general and attitudes toward marketing.

Skepticism which is seen as harmless can cause meaning changes. Two facts are suggested in marketing literature in order to expose this subject;

1. Insufficient information

2. Limited claim

Informative and Emotional Advertisement Tactics: In the advertisement process, different attractions are used in order to affect the target audience. These attractions appear in the ads in emotional or informative from or both emotional and informative form. Within this frame, we can investigate the ads in two tactics frame.

\section{LITERATURE REVIEW}

Moore and Moschis (1981) analyze the mass media and interpersonal influences on teenage consumer behavior and suggested that interpersonal communication with parents and peers about goods and services appears to contribute in child awareness of the relevant goods and services and development of consumer behavior due to various kinds of advertisement and media may be social process as it's the way to inform consumers. They also find out that a cognitive developmental approach may not accurately explain adolescent consumer socialization.

Adeolu B. Ayanwale et al. (2005) concluded that brand preferences does not exist in food drink industry, however, advertising helps in projecting product quality and value prior to the consumers. They regard the most effective of all media in advertising the product is television, because it combines motion, sound, and special visual effects and offers wide geographic coverage and flexibility when the message is presented. They also find out that advertisement should not be age oriented and selective and results showed that advertising does not varying impact on age group.

*Assistant Professor, Shyam Lal College

**Assistant Professor, Bhai Parmanand lnstitute of Business Studies 
Consumers high in skepticism toward advertising are influenced by a high price when brand familiarity is high but not when brand awareness is low. Consumer's low skepticism toward advertising is correlated to price regardless of brand familiarity (Hardest et al. 2002). For Less familiar brands, more skeptical consumers are confidently influence by high orientation price claims for most familiar brands it seems that because they discount instead of totally ignore the reference price claim (weilbaker et al. 1988). Consumer's evaluation to brand is negatively related to advertising skepticism (obermiller and spangenberg, 1998). Brand familiarity moderated by skepticism of advertising on the unstable price level. Consumers are more skeptical about biased than intention ad claims and are more skeptical about claims for practice than qualities of product. Consumers should be extra skeptical of belief than experience claims and consumers must be more skeptical of experience argue superior price than low priced product. It is also discussed that consumers experience toward the market place effect critical distinguishing feature affecting their reaction to advertising skeptics (Feick and Gierl, 1996).

It is concluded that, there is a partial effect of family socialization to ad skepticism toward brand information and family intergenerational transfer of ad skepticism to children and it is related to brand preference. It is found that overlap between ad skeptical beliefs about advertising and sales people, butt ad skepticism id different from skepticism from brand information (Obermiller and spangenberg, 2000). Moeere-shay and Lutz (1998) found that mothers were less trustful of advertising and less inclined to assume a positive price quality relationship. The result suggests that skepticism toward advertising is an attitude learned through interaction with parents, peers and televisions. It is suggested that relations with socialization mediator affects skepticism mainly for the reason that of its effects on teen's market place knowledge (Mangleburg and Bristol, 1998).

The interest in achieving positive immediate advertising response stems from findings that show that such a response is an important mediator variable in the link between ad exposure and the formation of an attitude toward the advertised offering (Mackenzie, Lutz and Belch 1986; Shimp 1981).
Demographic characteristics influence how individuals respond emotionally, but not to a huge extant and found that older viewers of the ad respond more emotionally towards the ad's than the younger viewers. Viewers who seen more ad's in their life time and no past experience with brand would more likely to find ad's not attractive than brand users and younger viewers for whom ad seems more unique. It is also suggested that individuals varies in their emotions, ability to recognize and interpret the ad (Stout and Rust, 1993).

Emotions and attitudinal components do appear between ad content and viewing time. Ad processing time (time compression) in viewer mind vary from ad to ads. Time compression had little effects on cognitive processing and post viewing attitude of viewers towards TV ads. Zinkhan and Burton (1989) indicate that viewer response to ad's have significant but unequal impact on attitude toward the brand and choice behavior. Advertising helps to catch the new and old cultural senses and devote them in consumer goods where they easily reachable to the consumer. Advertising changes according to the cultural changes to make ad messages more recognizable (Friedmann and Zimmer, 1988).

Lord and Burnkrant (1993) found that program involvement and dramatic attention devices used in television ads, there interaction with one another and with viewer's processing motivation, have the capacity to improve or delay the generation of viewer thoughts relevant to ad messages. If ad involvement is high, a low amplification program comes into view to be desirable. Public service broadcast messages attain audiences less motivated to attend to and intricate upon them.

The Viewer responses to frequent messages to a new product television commercial increase with frequency of exposure. Viewers appear to separate their negative feelings toward seeing the commercial again from their other attitude. Viewers, viewpoint about the advertisers influential intent, poor media planning and other associated factors may be responsible for division and initial formation of attitude toward new commercial requires partial amount of cognitive dealing out on the part of the consumer (Rethans et al. 1986). Joyful commercial viewed in the framework of a happy program was assessed more favorably than the same 
commercial viewed after experience to a sad program. Sad commercial, the reverse effects for this measure were obvious as this commercial execute more favorably in the situation of a sad program relative to a happy commercial (Kamins et al. 1991).

\section{OBJECTIVES}

The main objective of this study, is to find out the answers of the following questions -

- To find the importance of skepticism to advertisement in the effectiveness of advertisement attractions.

- To find the skepticism level towards emotional advertisement tactics.

- To find the relation between the informational ads tactics and skepticism.

\section{DATA ANALYSIS AND RESEARCH METHODOLOGY}

In order to find out the skepticism level of the participants the SKEP scale developed by Obermiller and Spangenberg (1998) is used. 22 of the participants were male and 35 of them were female. The reactions towards SKEP scale were consisting of five categories changing from "strongly agree" to "strongly disagree". The scale items were pointed as strongly agree $=1$ and strongly disagree $=5$. According to the factor analysis done, the answers were accumulated on the first factor mostly. The Cronbach alpha coefficients were calculated in order to determine that to what extent the scale units were related to each other and how homogenous the question group was. The alpha coefficient of the scale was founded out as $\square=.84$. This result shows that the inner consistency, in order words, the validity of the scale is high.

In order to find out the meaningful conceptual structure of the data from the application, the main components were analyzed by factor extraction method without using transformation method at first. At the end of the analysis, it was seen that two factors whose essence value were 1.00 and above were explaining the \% 62, 23 of the variance. The essence value of the two factors founded out as (4.10 and 1.49). It was observed that communalities of two factors defined in relation with the items were changing between 0.45 and 0.77 . These two important factors that appear at the end of the analysis seem to explain the most part of the total variance in the items and variance related to the scale.

When the "Component Matrix" table of the scale were examined, it was seen that the factor load value of 9 items were 0.50 and above. This finding shows that scale has a general factor. It is another proof of a general factor interval that the variance caused by first factor was $\% 45.5$ before transformation. The Kaiser-MeyerOlkin sampling sufficiency was founded out as (.81), and this shows that the sampling was sufficient.

\section{(REFER TABLE 1 HERE)}

These results show that the sampling group which consists of 57 people has a high skepticism structure.

In the second part of the research, 8 ads were selected in order to determine that in which advertisement tactics the audience has more trust. 98 ads broadcasted on prime time were recorded. Three instructors from Radio-TV Broadcasting Department selected four informative and four emotional ads from these. The informative ads were cleaning material (Cif krem; tells about how is the product makes cleaning), tooth paste (Colgate misvak; tells about the differences of the product from others), shampoo (Clear; tells about how product cleans hair) and food (Ülker Kellog's; gives information about calorie amount of the product). Emotional ads are beverage (Sprite; drinking and coolness), food (Eti Browni-cappuccino), dress (MaviJeans) and deodorant (Rexona). In order to understand that whether these ads are really informative and emotional, in other words to evaluate their validity and reliability, Puto and Wells Informational and Transformational Scale was used. Similar to real group 15 emotional and 8 informative, totally 23 itemed Scale was tried on 30 pre-graduate students. But firstly, this scale translated into Turkish. After watching every ads, participants were wanted to answer the five itemed scale which evaluate from (strongly agree/ strongly disagree). Results were measured for every ad separately and it was found out that the selected categories were supported. In the following table, the mean and standard deviations of every ad is given. When the arithmetic means of the ads are examined, it is seen that the means of informative 
and emotional ads are close to each other and arithmetic means support the category we selected.

\section{(REFER TABLE 2 HERE)}

For emotional ads while "informative" items in the scale has a mean between the interval of 2,79 and 2,93, the "emotional" items changes between 2,83 and 3,16 (five pointed scale). On the other hand, in the informative ads, the "emotional" items change between the interval of 2,88 and 2,74 . The informative items in these four ads show a mean between the interval of 3,18 and 2,90.

These defined their validity and reliability were provided 8 ads were showed to 57 students who were previously founded as skeptical after 4 weeks from the application of the scale. After every ad, the participants were wanted to range their ideas about the seven pointed brand attitude units. The simplest way of measuring the participants' attitudes towards objects like product class is to ask them whether or not they like the product or the brand (Batra, Myers \& Aaker, 1996, 251). For this goal, brand attitude units (very bad/very good and very undesirable/ very undesirable) were arranged as seven points.

In this research, in the evaluation of informative and emotional advertisement, the effect of the skepticism towards ad was tried to be analyzed. Advertisement evaluations were measured with two attitudes desirable/undesirable and good/bad.

\section{(REFER TABLE 3 HERE)}

Multiple regression analysis was used in order to find out the relation appeared against two different advertisement tactics. No meaningful relation between the both ad tactics and skepticism could be found. The regression coefficient that show the relation between skepticism and emotional ad was found as $\beta=, 093$ and it was $\beta=, 098$ for informative add tactics. When the t-test result about the meaningfulness of regression coefficient was examined, skepticism seemed not to be meaningfulness in the interpretation of ad tactics.

In order to interpret the results completely, the attitude result of ads are examined. In the following table, the means of emotional ads is more for from the skeptical groups than expected. For the emotional ads, the means of the participants with high skepticism rate were seemed to be changing between 3,15 and 2,05. In this seven pointed brand attitude scale it is seen that participants make positive interpretations about the ads they watched. From the seven pointed item intervals in the scale good/bad and desirable/undesirable, the second and third items seemed to be selected more. This is inversely proportional with the general skepticism inclination in the SKEP scale.

\section{(REFER TABLE 4 HERE)}

In the Table 5, the answers given to informative advertisement tactics are given to informative ads change between the interval of 4,38 and 3,19. When these means are examined, we can say that participants have a more negative attitude towards informative ads. The informative ads carry a higher negative attitude than emotional ads. However these inclinations are a lower coefficient than the one which we expected from skeptic approach. The answers of participants with high skepticism are more positive for emotional ads than informative ads.

\section{(REFER TABLE 5 HERE)}

\section{FINDINGS \& CONCLUSION}

In this research in which skepticism is accepted as an inclination, the impact of skepticism factor in interpreting the ad tactics is tried to be found out. In this research which accepts the skepticism as an inclination, this inclination is interpreted as a critical approach in resisting against advertisement messages and evaluating them. Skepticism towards advertisement can be thought as the main sales belief that helps the audience to form his/her reaction against advertisement.

According to the results of analysis, it was concluded that pre-graduate students between 18-24 ages created a general skepticism towards advertisements. However, they showed a positive attitude towards the selected eight ads in general. Therefore, no correlation was found between skepticism and ads. In the research when the means of informative and emotional ads are compared, it was seen that participants showed a more negative attitude towards informative ads. 
Also, in order to understand this study in a more practical way, a case study has been given for your knowledge.

\section{CASE STUDY}

"Et Tu, Brutus?” A Case for Consumer Skepticism and Backlash against Product Placements University of Manitoba

Marketers find themselves faced with the challenging task of creatively capturing and maintaining consumer attention. Two trends contribute to the search for unconventional methods for message delivery: the gradual adaptation of consumers to existing modes of marketing communications; and the increasing abundance of marketing messages that compete for limited consumer attention. Placing brands within media content (e.g., movies, T.V. programs, music) is one such method. This practice is termed as 'product placement'while brand sponsors pay for embedded commercial messages, this sponsorship frequently remains hidden (Balasubramanian 1994; Solomon and Englis 1996).

Placements are considered as cost-effective alternatives to advertising based on widely held assumptions (i.e., consumers are naïve and unwittingly consume marketing messages in the guise of entertainment due to the naturalistic and covert manner of brand inclusion) that may not necessarily bear out given the sophistication of audiences today. This assumed lack of persuasion knowledge is questioned based on contradicting anecdotal and pretest evidence: consumer speculations about the commercial intent of embedded messages and consequent skepticism are found to be high. Scant academic attention has been paid to the impact of variations in consumer awareness, except in the case of ethically controversial products (e.g., alcohol, tobacco) where public policy legislation is called for. The role of persuasion knowledge in generating a consumer backlash against placements (e.g., lowered trust in media and placed claims) remains unexplored. Important insights into the need for regulating placement activities may be gained from this research. If consumers are indeed more sophisticated than they are given credit for and possess adequate awareness and consequent mechanisms to cope with persuasive attempts, the call for government intervention may be unwarranted.

Further, investigations into placement efficacy have been limited to brand memory and evaluation (Babin and Carder 1996), and evidence available is ambiguous at best. Drawing upon tenets of the persuasion knowledge model (Friestad and Wright 1994) adds complexity to the placement efficacy construct (by also including trust in brand sponsors, the claims they make and trust placed in participating media). This suggests that the effectiveness of placements can be gauged from the point of view of all participants involved: for consumers (from a welfare perspective), for brand sponsors (from a brand and claim memory, attitudinal and trust perspective), and for participating media (from a trust and reputational perspective). Several issues thus warrant investigation: (a) Whether product placements are indeed as attractive as have been portrayed in past literature?; (b) Whether there are extenuating circumstances that might make advertisements more attractive?; (c) Whether product placement effects can prove to be a double edged sword for brand sponsors (by increasing memory on one hand, and hurting trust on the other) and for media (by generating additional revenue, yet potentially hurting its credibility); and (d) Whether government legislation of placement practices is needed in order to protect consumers that lack the ability to do so themselves?

The investigation focuses on consumer awareness of the covert commercial aspect of product placements and the consequent impact on placement efficacy. The 2 key hypotheses tested are: memory for placed brands and claims is higher than the memory for advertised brands (in line with past research); and awareness of commercial intent moderates the effect of the trust in brands, claims made and media used, such that high awareness leads to lowered trust for claims and lowered perceptions of motive purity for media used, when brands are placed versus when they are advertised. In other words, placed claims are expected to enhance memory. At the same time, a potential backlash can occur if consumers become aware of the hidden commercial intent of sponsors. This backlash would not occur when awareness is low and no commercial intent is perceived. 
Consumers are already aware of the commercial nature of advertisements, and the question of feeling manipulated and consequent backlash does not arise here. Results support the proposition that though people appear to remember placed claims better, it may sometimes be better to advertise brands. Media managers in addition need to understand that repercussions to covertly embedding brands within the programming or editorial content are possible.

Three laboratory experiments (two conducted, one planned) test these hypotheses. Study 1 uses a paperbased scenario about brand placements for a fictional vitamin brand within a hypothetical magazine article. Awareness of commercial intent is manipulated, and the trust in brands, perceived motive purity of the medium involved, and feelings of betrayal in the medium are measured. Study 2 uses more realistic stimuli (presented as excerpts from a hypothetical magazine), measures awareness of commercial intent, and compares persuasion outcomes when claims about an unfamiliar brand of instant soup are placed versus advertised. Memory as well as trust measures for the brand and the medium are measured. Results bear out the proposition that placements can lead to better memory outcomes, yet they also have the potential to create a backlash if consumers feel they are being manipulated via covert marketing attempts. This dual nature of placements is under investigated in existing placement literature and the implications for media tend to be ignored. In Study 3 we propose to investigate whether this backlash gets exacerbated when placements are discerned in highly credible media. Since consumers tend to hold credible media up to a higher standard of conduct, they may feel even more betrayed since such conduct would not be within the realm of their expectations.

\section{REFERENCES}

1. Ayanwale, Adeolu B. Ayanwale et al. (2005). The Influence of Advertising on Consumer Brand Preference.

2. Babin, L. A., \& Carder, S. (1996). Viewers' recognition of brands placed within a film. International Journal of Advertising, 15, 140-151.

3. Balasubramanian, S. K. (1994). Beyond advertising and publicity: Hybrid messages and public policy issues. Journal of Advertising, 23, 29-46.

4. Batra, R. \& Myers, J. G. \& Aaker D.A. (1996). Advertising Management. (5th ed.) New Jersey: Prentice Hall.

5. Boush, D. M., Friestad, M \& Rose G. M. (1994). "Adolescent Skepticism toward TV Advertising and Knowledge of Advertiser Tactics" Journal of Consumer Research, 21, 165-175.

6. Campbell, M. C. (1995) "When Attention-Getting Advertising Tactics Elicit Consumer Inferences of Manipulative Intent: The Importance of Balancing Benefits and Investments" Journal of Consumer Psychology. 4 (3). 225-254.

7. Chaiken, S. (1980). "Heuristic versus Systematic Information Processing and the Use of Source versus Message Cues in Persuasion" Journal of Personality and Social Psychology. 39(5), 752-766.

8. Ergeç, N.E. (2003). Televizyon Reklamlarına Yönelik Şüphe (İkna Bilgi Modelinin Yorumlanmas1). Eskişehir: Anadolu Üniversitesi Yay. No: 1553.

9. Feick and Gierl (1996). Skepticism About Advertising: A Comparison of East and West German Consumers. International Journal of Research

10. Ford, G. T., Smith, B.D. \& Swasy, J.L. (1990). "Consumer Skepticism of Advertising Claims: Testing Hypotheses from Economics of Information", Journal of Consumer Research.16: 433-441.

11. Forehand, M. \& Grier, S. (2000). "Paying Attention to Intention: Inoculating the Firm against Consumer Skepticism”. Research Paper Series. Stanford University. Graduate School of Business. Research paper no: 1665.

12. Forehand, M. \& Grier, S. (2002). "When is Honesty the Best Policy? The Effect of Stated Company Intent on Consumer Skepticism" Research Paper Series. Standford University. Graduate School of Business. Research paper no: 1665.

13. Friedmann and Zimmer (1988). "The Role of. Psychological Meaning in Advertising," Journal of Advertising, 17. (1), 31-40.

14. Friestad, M., \& Wright, P. (1994). The persuasion knowledge model: How people cope with persuasion attempts. Journal of Consumer Research, 21, 1-31.

15. Kamins et al. (1991). "An Investigation into the 
'Match-Up' Hypothesis in Celebrity Advertising: When Beauty May be Only Skin Deep," Journal of Advertising, 19 (1), 4-13.

16. Lord and Burnkrant (1993). "Attention versus Distraction: The Interactive Effect of Program Involvement and Attentional Devices on Commercial Processing," Journal of Advertising, 22, 47-60.

17. Mangleburg, Tamara F. and Terry Bristol "Socialization and Adolescents' Skepticism toward Advertising” Journal of Advertising 27 (3) Fall, 1121, 1998.

18. Moeere-shay and Lutz (1998). Impact of Viewer Response Profile on Skepticism toward Advertising

19. Obermiller, C. \& Spangenberg, E. \& MacLachlan, D.L. (2005) “Ad Skepticism-The Consequences of Disbelief” Journal of Advertising, 34 (3), 7-17.

20. Obermiller, C. \& Spangenberg, E.R. (2000). “On The Origin and Distinctness of Skepticism toward Advertising” Marketing Letters. 11(4): 311-322.

21. Obermiller, C. \& Spangenberg, E.R. (1998). "Development of a Scale to Measure Consumer Skepticism toward Advertising” Journal of Consumer Psychology. (2):159-186.

22. Petty,R.E. \& Cacioppo, J.T. (1984). "The Affects of Involvement on Responses to Argument Quantity and Quality: Central and Peripheral Routes to Persuasion" Journal of Personality and Social Psychology. 46. (1), 69-81.

23. Priester, J.R. \& Petty, E.R (1995). "Source Attributions and Persuasion: Perceived Honesty as a Determinant of Message Scrutiny" Personality and Social Psychology Bulletin, 21 (June), 637-654.

24. Puto, C.P. \& Wells W.D. (1984). "Informational and Transformational Advertising: The Differential Effects of Time", Advances in Consumer Research, 11, 638-643.

25. Rethans et al. (1986). "Effects of television commercial repetition, receiver knowledge, and commercial length: a test of two-factor model", Journal of Marketing Research, 23, 1, 50-61.

26. Ritchie, R. J. B. \& Darke,P.R. (2000) "In the Shadow of Doubt: Advertiser Deception and the Defensive Consumer" Poster Session Presented at the Association for Consumer Research Conference, Salt Lake City, UT.

27. Ritchie, .R. J. B. (2001). The Mutable Meaning of Ads: Advertising thorough the Eyes of the Skeptical
Consumer. Faculty of Commerce. University of British Columbia. Working Paper-Version.

28. Solomon, M., \& Englis, B.G. (1996). Consumption constellations: Implications for integrated communications strategy. In: Thorson E.and Moore J., editors. Integrated Communication: Synergy of Persuasive Voices. Mahwah, NJ: Erlbaum, pp. 6586. 
Table 1. Factor Analysis Results of SKEP Scale

\begin{tabular}{|c|c|c|c|c|}
\hline Items & Communalities & Component & Mean & Std. Dev. \\
\hline 1-We can depend on getting the truth in most advertising & ,63 & ,76 & 3,8 & 1,0 \\
\hline 2-Advertising's aim is to inform the consumer & ,77 & ,72 & 2,2 & 1,0 \\
\hline 3-I believe advertising is informative & ,69 & ,64 & 2,9 & 1,0 \\
\hline 4- Advertising is generally truthful & ,73 & ,75 & 3,6 & 0,9 \\
\hline \multicolumn{5}{|l|}{ 5- Advertising is a reliable source of information about } \\
\hline the quality and performance of products &, 57 & ,73 & 3,5 & 1,0 \\
\hline 6-Advertising is truth well told & ,49 & 70 & 3,5 & 0,9 \\
\hline \multicolumn{5}{|l|}{ 7-In general, advertising presents a true Picture of the } \\
\hline product being advertised & ,45 &, 50 & 3,3 & 1,2 \\
\hline \multicolumn{5}{|l|}{ 8-I feel I've been accurately informed after viewing most } \\
\hline advertisement &, 55 & ,72 & 3,6 & 0,9 \\
\hline $\begin{array}{l}\text { 9-Most advertising provides consumers with essential } \\
\text { information }\end{array}$ & ,68 & ,69 & 2,9 & 1,0 \\
\hline
\end{tabular}

Table 2. Scale Means for Each Commercial

\begin{tabular}{|llll|}
\hline Viewing Order and Product Class & Judges' Classification & $\begin{array}{l}\text { Information mean } \\
* * \text { (std.dev.) }\end{array}$ & $\begin{array}{l}\text { Transform mean } \\
* * \text { (std.dev. }\end{array}$ \\
\hline 1-toothpaste (colgate) & INF & $3,18(, 50)$ & $2,84(, 38)$ \\
2-cleaning materials (Cifkrem) & INF & $2,91(, 43)$ & $2,74(, 41)$ \\
3-shampoo (Clear) & INF & $2,90(, 44)$ & $2,88(, 35)$ \\
4-food(Ülker ellogs) & INF & $3,15(, 46)$ & $2,79(, 42)$ \\
5-beverage (Sprit) & TRANS & $2,82(, 47)$ & $3,16(, 41)$ \\
6-dress(Mavi jeans) & TRANS & $2,81(, 50)$ & $2,83(, 50)$ \\
7-food (Eti browni) & TRANS & $2,93(, 38)$ & $3,03(, 40)$ \\
8-deodorant (Rexsona) & TRANS & $2,79(, 39)$ & $3,00(, 38)$ \\
\hline
\end{tabular}

Table 3. SKEP and Emotional or Informational Ads

\begin{tabular}{|llll|}
\hline & Regression weight $\beta$ & Standard error & $\mathrm{T}$ \\
\hline SKEP-EMOT &, 093 &, 117 &, 624 \\
SKEP-INFO &, 098 &, 116 &, 660 \\
$\mathrm{R}=0,113 \mathrm{R}^{2}=0,013 \mathrm{~F}=0,316$ & & & \\
\hline
\end{tabular}

Table 4. Descriptive Statistic of Emotional Ads

\begin{tabular}{|llllll|}
\hline Ads & N & Minimum & Maximum & Mean & Std. Deviation \\
\hline Eti (good/bad) & 57 & 1,00 & 7,00 & 2,5769 & 1,4865 \\
Rexsona & 57 & 1,00 & 6,00 & 3,1538 & 1,6731 \\
Sprite & 57 & 1,00 & 7,00 & 2,1538 & 1,5131 \\
Mavi jeans & 57 & 1,00 & 7,00 & 2,2500 & 1,4400 \\
\hline
\end{tabular}




\begin{tabular}{|llllll|}
\hline Eti(desirable/undesirable) & 57 & 1,00 & 5,00 & 2,5000 & 1,1964 \\
Rexona & 57 & 1,00 & 7,00 & 3,0769 & 1,6431 \\
Sprite & 57 & 1,00 & 7,00 & 2,0577 & 1,4199 \\
Mavi jeans & 57 & 1,00 & 7,00 & 2,3654 & 1,4823 \\
Valid N (list wise) & 57 & & & & \\
\hline
\end{tabular}

Table 5. Descriptive Statistics of Informational Ads

\begin{tabular}{|llllll|}
\hline Ads & N & Minimum & Maximum & Mean & Std. Deviation \\
\hline Colgate (good/bad) & 57 & 1,00 & 7,00 & 3,8846 & 1,4370 \\
Clear & 57 & 1,00 & 7,00 & 4,0577 & 1,6016 \\
Cif & 57 & 1,00 & 7,00 & 3,1923 & 1,9204 \\
Ülker & 57 & 1,00 & 7,00 & 4,3846 & 1,8698 \\
Colgate (desirable/undesirable) & 57 & 1,00 & 7,00 & 3,9423 & 1,3197 \\
Clear & 57 & 1,00 & 7,00 & 4,0577 & 1,5135 \\
Cif & 57 & 1,00 & 7,00 & 3,2308 & 1,8216 \\
Ulker & 57 & 1,00 & 7,00 & 4,3654 & 1,8580 \\
Valid N (listwise) & 57 & & & & \\
\end{tabular}

